\title{
Validation of the Spanish Version of the Arizona Sexual Experience Scale (ASEX) Using Self-Reported and Psychophysiological Measures
}

\section{María del Mar Sánchez-Fuentes, Nieves Moyano², Reina Granados ${ }^{3}$ y Juan Carlos Sierra $^{3 *}$}

'Facultad de Ciencias Humanas y Sociales, Departamento de Psicología del Individuo, Universidad de la Costa (CUC), Barranquilla, Colombia.

${ }^{2}$ Facultad de Ciencias Humanas y de la Educación, Departamento de Psicología y Sociología, Universidad de Zaragoza, Huesca, España.

${ }^{3}$ Mind, Brain and Behavior Research Center (CIMCYC), Universidad de Granada, Granada, España.

- Recibido: 03 - 04 - 2018 . Aceptado: 1 - 10-2018 . Avance online: $21-11-2018$

ABSTRACT: Assessment of sexual response and sexual functioning through self-reported measures is of relevance in the area of sexual health. The goal was to analyze the psychometric properties of the Spanish version of the Arizona Sexual Experience Scale (ASEX) in a sample of 1,105 individuals divided into two subsamples to examine and confirm the factorial structure. To evaluate both psychophysiological and subjective sexual arousal, we considered, from the total sample, 49 participants who took part in a second phase of the study. They were exposed to sexual films and they also answered the Spanish version of the ASEX, Massachusetts General Hospital Sexual Functioning Questionnaire, Sexual Opinion Survey-6, and Sexual Inhibition/Sexual Excitation Scales-Short Form. Results showed that ASEX has an unidimensional structure, good internal consistency, and construct, convergent, and discriminant validity. The scale examined it is useful measure for the assessment of sexual functioning for both clinical and research purposes.

KEYWORDS: Arizona Sexual Experience Scale; Sexual functioning; Reliability; Validity; Genital response.

Validación de la Versión Española de la Arizona Sexual Experience Scale (ASEX) usando medidas autoinformadas y psicofisiológicas

RESUMEN: La evaluación de la respuesta sexual y el funcionamiento sexual a través de medidas autoinformadas es relevante en el área de la salud sexual. El objetivo fue analizar las propiedades psicométricas de la Arizona Sexual Experience Scale (ASEX) en una muestra de 1.105 individuos, divididos en dos submuestras para explorar y confirmar la estructura factorial. Para evaluar la activación sexual subjetiva y psicofisiológica, de la muestra total se seleccionaron 49 sujetos, los cuales participaron en una segunda fase del estudio. Estos últimos participantes visualizaron un vídeo con contenido sexual explícito, completaron las versiones españolas del ASEX, Massachusetts General Hospital Sexual Functioning Questionnaire, Sexual Opinion Survey-6 y Sexual Inhibition/Sexual Excitation Scales-Short Form. Tras los resultados se comprueba que el ASEX tiene una estructura unidimensional, buena consistencia interna y validez de constructo, convergente y discriminante. La escala examinada es útil para la evaluación del funcionamiento sexual, tanto con fines clínicos como de investigación.

PALABRAS CLAVE: Arizona Sexual Experience Scale; Funcionamiento sexual; Fiabilidad; Validez; Respuesta genital.

Sexual dysfunctions are a key aspect when evaluating sexual health (World Health Organization, 2015). Thus, sexual functioning

*Correspondence: Juan Carlos Sierra.

Facultad de Psicología, Campus Universitario de Cartuja.

CP: 18011, Granada, España

E-mail: jcsierra@ugr.es

(C) 2018 Sociedad Universitaria de Investigación en Psicología y Salud. Publicado por Consejo General de Colegios Oficiales de Psicólogos, España. Este es un artículo Open Access
bajo la CC BY-NC-ND licencia (http://creativecommons.org/licencias/by-nc-nd/4.0/). is shown to be linked with quality of life. Sexual dysfunctions are considered a disturbance in any of the phases of sexual response that cause clinically significant distress in other important areas of functioning. Nowadays, the Diagnostic and Statistical Manual of Mental Disorders (DSM-5) includes four male-related sexual disorders (Delayed Ejaculation, Erectile Disorder, Male Hypoactive Sexual Desire Disorder, and 
Premature Ejaculation), three female-related sexual disorders (Female Orgasmic Disorder, Female Sexual Interest/Arousal Disorder and Genito-Pelvic Pain/Penetration Disorder) and one disorder for both sexes (Psychiatric Substance/ Medication-Induced Sexual Dysfunction) (American Psychiatric Association, 2013). Sexual dysfunctions are prevalent. Around 30\% of men and $40 \%$ of women report at least one sexual dysfunction (Laumann, Paik, \& Rosen, 1999; Palacios, Castaño, \& Grazziotin, 2009). In Spain, the prevalence is also high, ranging from 32 to 39 percent of men and from 45 to 58 percent of women (Sierra, Vallejo-Medina, Santos-Iglesias, \& Lameiras-Fernández, 2012).

A fast procedure to identify sexual function impairments is the use of brief self-reported measures, such as the Arizona Sexual Experience Scale (ASEX; McGahuey et al., 2000). The ASEX is composed of five items that assesses sexual functioning on five areas: sexual interest, sexual arousal, erection (for men), vaginal lubrication (for women), ability to reach orgasm, and satisfaction with orgasm. The answer choices are on a 6-point Likert ( 1 = hyperfunction to $6=$ hypofunction), with higher scores indicating poorer sexual functioning. This measure has shown adequate reliability, both internal consistency with Cronbach's alpha values equal to .90 , and test-retest reliability in psychiatric patients $(r=.80, p<.01)$ and in non-clinical individuals $(r=.89, p<.01)$. Moreover, evidence of validity is shown, such as convergent validity, by correlations with other measures of sexual functioning, and discriminant validity (McGahuey et al., 2000). The ASEX has been adapted to different countries and populations, such as France, in which research based on depressed individuals have been conducted (Briki et al., 2014); in Thailand, with patients with Parkinson's disease (Jitkritsadakul, Jagota, \& Bhidayasiri, 2014); in Tunisian patients with schizophrenia (Nakhli et al., 2014); and in Turkish patients with symptoms related to end-stage renal disease (Soykan, 2004). In all of these studies, the ASEX has shown adequate psychometric properties. In Spain, although there is a validated brief selfreport measure to evaluate sexual functioning, (namely, the Massachusetts General Hospital Sexual Functioning Questionnaire (MGH-SFQ; Sierra et al., 2012), this measure does not include any items to assess subjective sexual arousal derived from vaginal lubrication in women.
Therefore, the objective of the current research was to analyze the psychometric properties of the ASEX in a sample from the Spanish general population. The specific objectives were: (a) to examine the factorial structure in men and women; (b) to examine the internal consistency and psychometric properties of the items; and (c) to provide evidence of validity such as construct, concurrent and discriminant, with other selfreported measures and physiological data from sexual arousal. The following hypotheses were tested:

H1. Higher scores from the ASEX will be negatively associated with scores from the $\mathrm{MGH}$ SFQ (Sierra et al., 2012).

H2. Better sexual functioning will be associated with erotophilia (Granados, Salinas, \& Sierra, 2017; Sánchez-Fuentes, Salinas, \& Sierra, 2016), with higher propensity for sexual arousal (Moyano \& Sierra, 2014), and with less propensity for sexual inhibition due to both the fear of sexual performance failure and the risk of being caught/ getting Sexually Transmitted Infections during sexual activity (Bancroft, Graham, Janssen, \& Sanders, 2009; Moyano \& Sierra, 2014).

H3. Participants with worse sexual functioning will show lower objective sexual arousal (Sarin, Amsel, \& Binik, 2014) and lower subjective sexual arousal (Laan, van Driel, \& van Lunsen, 2008).

\section{METHOD}

\section{- PARTICIPANTS}

We used two independent samples. The first sample consisted of 400 participants $137.75 \%$ men and $62.25 \%$ women) and was used for Exploratory Factor Analysis (EFA). The second sample composed of 705 subjects $(42.13 \%$ men and $57.87 \%$ women) was used to perform the Confirmatory Factor Analysis (CFA) and to obtain evidence of validity. Both samples were similar based on gender $\chi^{2}=2.02 ; p=.08$; having a sexual relationship $\chi^{2}=2.64 ; p=.06$, and their number of sexual partners ${ }_{(977)}=1.41 ; p=.16$. However they significantly differed in age $\dagger_{(1,089)}=$ $6.45 ; p=.000$; the type of relationship $\chi^{2}=$ $4.63 ; p=.037)$, education $\chi^{2}{ }_{(3)}=56.44 ; p=.000$; age of their first sexual encounter $t_{(1,077)}=2.72$; 
Table 1

Socio-demographic and psychosexual characteristics

\begin{tabular}{|c|c|c|c|c|c|}
\hline & & & & & \\
\hline & $M / \%$ & $S D$ & $M / \%$ & $S D$ & $x^{2} / t$ \\
\hline Education & & & & & $14.99 * *$ \\
\hline No education & 1.10 & & 1.10 & & \\
\hline Primary school & 4.30 & & 2.20 & & \\
\hline Secondary school & 49.50 & & 60.60 & & \\
\hline University & 45.00 & & 36.10 & & \\
\hline Romantic relationship & 72.1 & & 73.8 & & 0.40 \\
\hline Type of relationship & & & & & $13.77^{* * *}$ \\
\hline Dating & 41.30 & & 56.70 & & \\
\hline Married & 58.70 & & 43.30 & & \\
\hline Length of relationship (years) & 5.35 & 2.88 & 5.84 & 4 & $2.33^{* \star *}$ \\
\hline Having a sexual relationship & 97.50 & & 98.80 & & 1.73 \\
\hline Age of first sexual relationship & 17.75 & 3.25 & 17.15 & 2.39 & $0.93^{* *}$ \\
\hline Number of sexual partners & 10.75 & 10.75 & 5.84 & 8.49 & $33.98^{* * *}$ \\
\hline
\end{tabular}

$p=.007)$, and length of their relationship $t_{(1,089)}=$ $-1.67 ; p=.004)$. In particular, the second sample, in contrast to sample 1, were older $(M=33.92$; $S D=14.03$ vs. $M=28.52 ; S D=11.96)$, had a greater number of married individuals $(53 \%$ vs. $44 \%)$, with university degree (47\% vs. $26.1 \%)$, older at their first sexual encounter $(M=17.55$; $S D=2.88$ vs. $M=17.09 ; S D=2.58)$ and with a longer relationship $(M=11.67 ; S D=11.08$ vs. $M=9.16 ; S D=10.81$ ).

The overall sample consisted of 1,105 Spanish heterosexual participants $(40.50 \%$ men and $59.50 \%$ women), ranging age from $18-72$ years. The mean age of men was 34.92 (SD = 13.37) and mean age of women was 29.93 (SD = 13.33), with statistically significant differences in age $t_{(1,1,088)}=6.05 ; p<.001$. Table 1 shows the sociodemographic and psychosexual characteristics for men and women.

Of those 1,105 participants, 25 men and
24 women participated in a second phase of the study, in an experimental laboratory condition. The mean age of men was $20.71(S D=1.73)$ and mean age of women was $20.64(S D=2.14)$. They were all undergraduate students, heterosexuals, and reported having had sex at least once in their lifetimes.

\section{- INSTRUMENTS AND MATERIALS}

Background Questionnaire. We gathered information on participants' sex, age, educational level completed, and nationality. In addition, information was collected about sexual orientation, current relationship status, length of their current relationship, whether they engaged in sexual activities with their current partner, age of their first sexual experience (oral, vaginal, and/or anal), and number of sexual partners with whom they had had sexual activity (oral, vaginal and/or 
anal). Additionally, participants who went through the experimental laboratory condition were also asked to indicate whether they had a physical or sexual disease, a psychological disorder, and whether they took medications or drugs over the past 30 days.

Spanish version of Arizona Sexual Experience Scale (ASEX; McGahuey et al., 2008). Characteristics of the scale have been previously described.

\section{Spanish adaptation of Massachusetts} General Hospital Sexual Functioning Questionnaire (MGH-SFQ; Sierra et al., 2012). This questionnaire was composed of five items assessing sexual functioning during the past month: sexual interest, sexual arousal, orgasm, erection (only for men) and overall sexual satisfaction. This questionnaire was answered using a 5-point Likert scale $(0=$ totally reduced to $4=$ normal), higher scores indicated better sexual functioning. The Spanish adaptation showed good psychometric properties (Sierra et al., 2012). In this study, Cronbach's alpha values were .86 for men and .90 for women.

\section{Spanish version of Sexual Opinion Survey-6} (SOS-6; Vallejo-Medina, Granados, \& Sierra 2014). This survey was composed of six items that assesses sexual attitudes, i.e., erotophobiaerotophilia. Respondents rated their sexual attitudes on six 7-point ( $1=$ totally disagree to 7 = totally agree), with higher scores indicating greater erotophilia. The Spanish questionnaire showed good psychometric properties (VallejoMedina et al., 2014). In this study, Cronbach's alpha values were .63 for men and .75 for women.

\section{Spanish version of Sexual Inhibition/Sexual} Excitation Scales-Short Form (SIS/SES-SF; Moyano \& Sierra, 2014). This scale has 14 items divided into three factors: (a) Sexual Excitation Scale (SES) that evaluates sexual arousal derived from social interactions; (b) Sexual Inhibition Scale-1 (SIS1) that includes items referring to distraction/concentration in sexual performance; and (c) Sexual Inhibition Scale-2 (SIS2) that includes items referring to the risk of being discovered or contracting some type of sexually transmitted infection. Answer choices were on a 4 -point Likert scale ( $1=$ completely agree to 4
= completely disagree), however, scores were recoded following the authors' recommendations ( 1 = completely disagree to $4=$ completely agree). Higher scores indicated greater sexual excitation and greater sexual inhibition. The Spanish adaptation showed good psychometric properties (Moyano \& Sierra, 2014). In this study, Cronbach's alpha values were .72 and .73 in SES; .68 and .62 in SIS 1 and; .63 and 70 in SIS2 for men and women, respectively.

Spanish version of the Ratings of Sexual Arousal (RSA; Sierra et al., 2017). This scale consisted of five items (sexual arousal, genital sensations, sexual warmth, non-genital physical sensations and sexual absorption) that assessed subjective sexual arousal to an erotic stimulus. Answer choices were on a 7-point Likert ( $1=$ none to 7 = extreme), with higher scores indicating greater sexual excitation. The Spanish adaptation showed good psychometric properties (Sierra et al., 2017). In this study, Cronbach's alpha values were .85 for men and .91 for women.

Spanish version of Ratings of Genital Sensations (RSG; Sierra et al., 2017). This questionnaire consisted of a single item with 11 response options that described genital sensations in increasing order of sexual activation, where 1 indicated "no genital sensation" and 11 indicated "multiple orgasm". Respondents were instructed to select the response option that indicated his/her highest level of genital sensations experienced to any sexual stimulus. Thus, higher scores indicated greater subjective sexual arousal. The Spanish adaptation showed good psychometric properties (Sierra et al., 2017).

Psychophysiological measures - Genital Response. Men's genital responses were measured using an indium-gallium strain gauge (Janssen, Vissenberg, Visser, \& Everaerd, 1997). This device measures changes in the circumference of the penis when an erection is occurring. To measure the genital response of women's vaginal pulse amplitude (VPA), a photoplethysmograph was used (Laan, Everaerd, \& Evers, 1995). To obtain and process data from both sexes, we used Biopac MP150 system with Acqknowledge Software 4.2.0 (BIOPAC Systems, Inc., Goleta, CA, USA). VPA signal was sampled at 1,000 $\mathrm{Hz}$ and high-pass-filtered $(1 \mathrm{~Hz})$. Each of the 
VPA signals were visually examined, eliminating motion artefacts. After, we calculated each peakto-peak amplitude.

Visual stimuli. Stimuli included two films: a 3-minute neutral film in order to establish a baseline, i.e., nature documentary in which no individuals or animals appeared; and a 3-minute erotic film that consisted of a sexual interaction represented by a heterosexual couple. In the erotic film, three specific interactions were distinguished: 1-minute fellatio, 1-minute cunnilingus, and 1 -minute vaginal intercourse. The erotic film was selected from a series of several videos, with this video being the one that individuals reported the highest level of subjective sexual arousal (see Sierra, Granados, Sánchez-Fuentes, Moyano, \& López, 2015).

\section{-PROCEDURE}

First, participants answered the self-reported measures in an online format, this is the procedure commonly used in human sexuality research (see Sierra, Moyano, Vallejo-Medina, \& GómezBerrocal, 2018). The URL was distributed by the news service of the University of Granada and by social networking. The first page of the survey included an informed consent form. It explained that the overall objective of the study was to examine different factors of human sexuality, and that inclusion criteria were: (1) being 18 years old or older; (2) having Spanish citizenship; and (3) identifying as heterosexual. Then, once the individuals had given their consent to participate, they proceed to answer the survey. We also used a paper and pencil procedure to assess people 50 years old or older, in order to reduce limitations of the online format, due to selection bias in the sample, as younger individuals use Internet more often than older people.

A similar procedure was used for the participants who were students of the University of Granada. These participants were informed that they would be required to participate in the second phase of the study; in which they would be invited to the Human Sexual Laboratory, considering some of their responses to the selfreported measures. Exclusion criteria were: having a psychological disorder, having a sexual and/ or medical problem, using medications such as antidepressants, antihypertensive, antipsychotics and/or drugs/alcohol that could interfere with sexual function, and having suffered sexual abuse.

For the second phase of the study, we selected the participants who met the inclusion criteria and contacted them by e-mail. Women were not evaluated during their menstruation. In addition, all participants were required to avoid consumption of caffeine, alcohol and also to refrain from sexual activity during the 24 hours prior to the experimental session, in order to reduce other physiological influences. Once participants entered the laboratory, they were told that the experimental task consisted of them watching a documentary first, and then watching a film with explicit sexual content. An instructor of the same sex as the participant explained how to place the plethysmograph (for men) and photoplethysmograph (for women) in their bodies. All participants signed informed consents and were informed of the possibility of withdrawing from the study at any time. Prior to film projection, the participants waited for five minutes in the experimental room with the instrument in place for habituation purposes. The films were shown on a 24-in plasma TV. After each film projection, the participant was required -by instructions presented in the screen- to fulfill the RSA and RSG scales (Sierra et al., 2017).

This study was approved by the Ethics Committee on Human Research of the University of Granada (Spain). The sample was recruited among the general Spanish population and the students of University of Granada, by means of a nonrandom sampling procedure. All participants were volunteers and received no compensation for their participation.

\section{RESULTS}

\section{-EXPLORATORY FACTOR ANALYSIS (EFA)}

We performed a Parallel Analysis with FACTOR 10.4. We employed a Principal Component Analysis (PCA). In men, a unidimensional structure was obtained, which explained 48\% of the variance (eigenvalue $=2.39$ ). Factor loadings ranged from .62 (item 5) to .77 (item 2) and communalities ranged from .38 to .60 (from items 5 and 2 respectively). Similarly, in women, a unidimensional structure was yielded, which explained $50.5 \%$ of the variance (eigenvalue = 2.52). Factorial loadings from the items oscillated 
Table 2

Factor loadings and communalities $\left(\mathrm{h}^{2}\right)$ for the ASEX in men and women

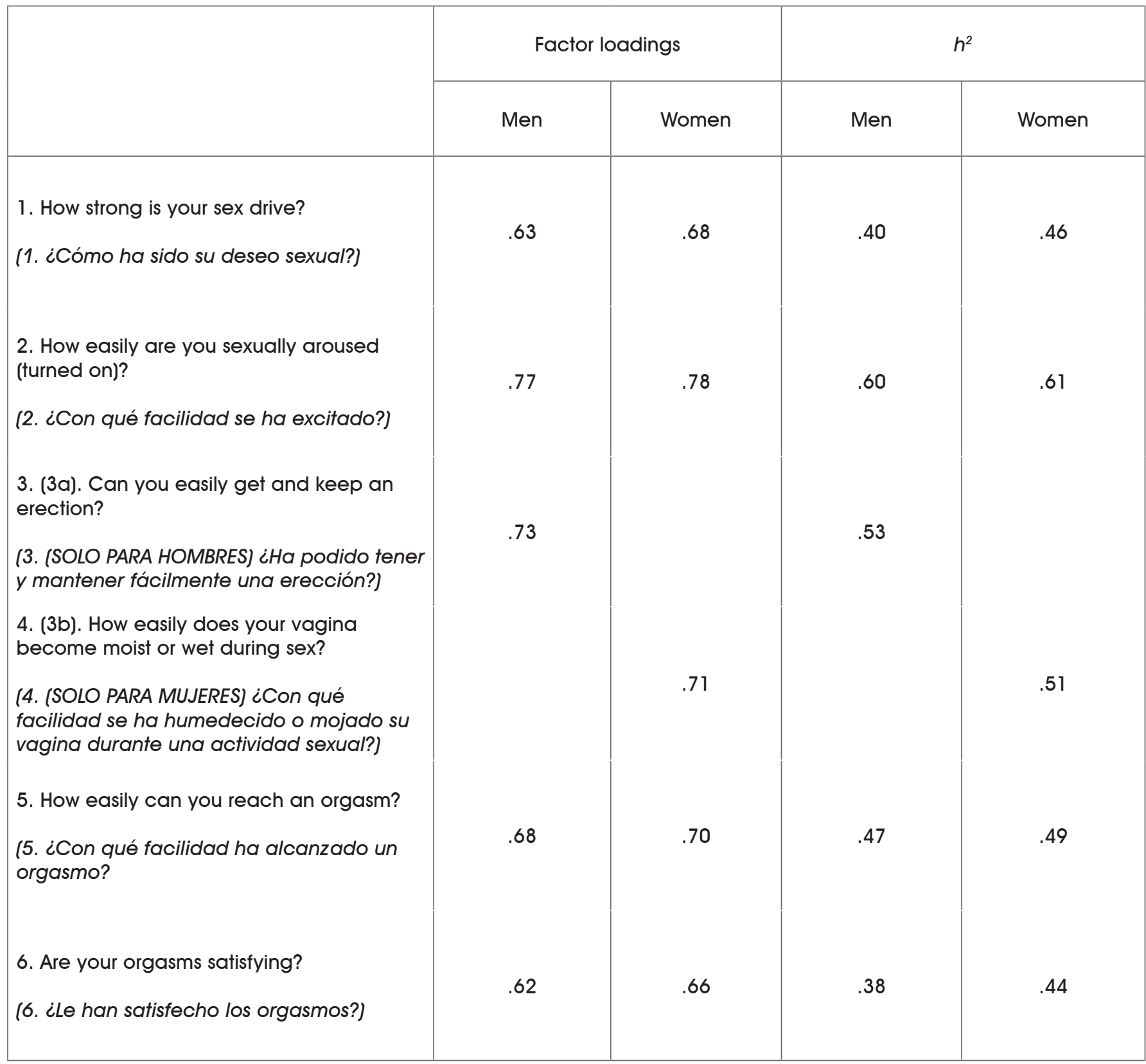

between .66 (item 5) and .78 (item 2), and their communalities between .44 and .61 of the above items respectively. Table 2 shows the factor loadings and communalities $\left(h^{2}\right)$.

\section{- CONFIRMATORY FACTOR ANALYSIS (CFA)}

We considered skewness and kurtosis for the items of the ASEX. In men, items showed normality, as values were between -1 and 1 (skew $=0.32$ to 0.73 and kurtosis $=-0.09$ to 0.36 for items 1 and 3 respectively), however item 6 showed some skewness $(-1.12)$ and kurtosis
(2.43). Participant's responses for item 6 "Are your orgasms satisfying?" were negatively skewed $(M=2.23 ; S D=.89)$, indicating that they are incline to report to be satisfied with their orgasms. In women, while most of the items were distributed normally (skew $=0.28$ to 0.47 for items 2 and 4 respectively and kurtosis $=-0.28$ to 0.18 for items 5 and 1, respectively), again item 6 showed some skewness and kurtosis (1.53 and 2.65 respectively). Answers from women were also negatively skewed $(M=2.32 ; S D=1.11)$.

We tested the one factorial structure. Confirmatory analysis was conducted using 


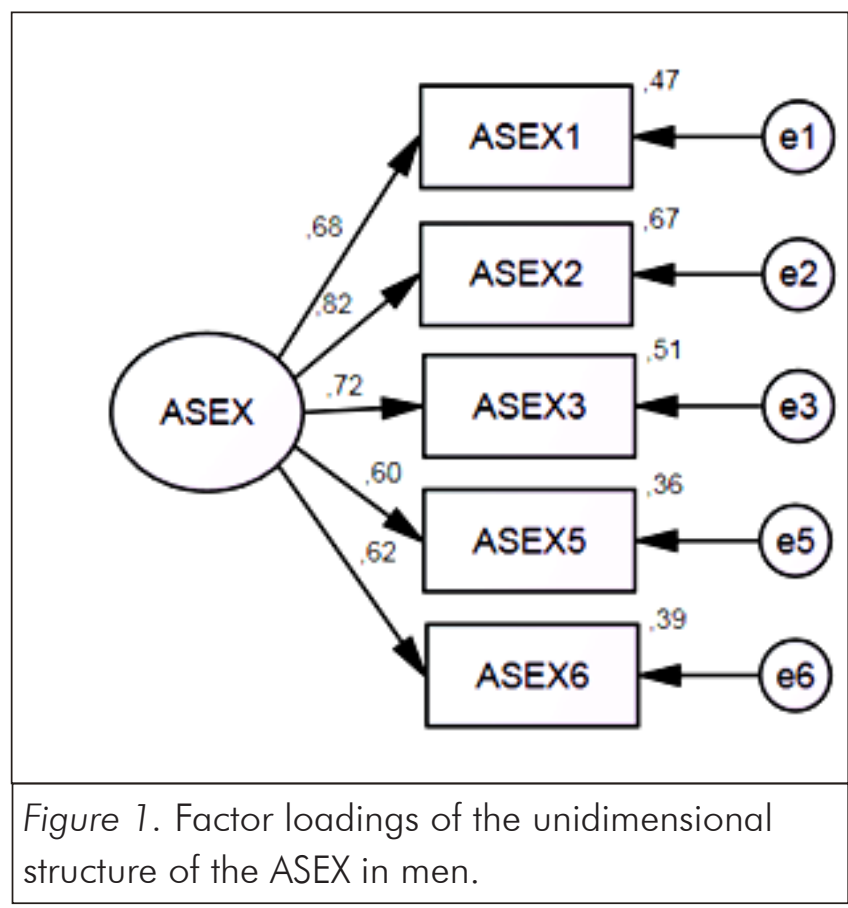

the AMOS 7.0 software package. Fit indexes included: (i) the Root Mean Square Error of Approximation (RMSEA); (ii) the 90\% confidence interval for RMSEA; (iii) the Comparative Fit Index (CFI); and (iv) the Tucker-Lewis Index. RMSEA values lower than .06 indicates a good fit, values under 10 could be considered as an acceptable fit (Browne \& Cudeck, 1993). Upper values for the $90 \%$ confidence interval of less than .08 also indicate a good fit. CFI and TLI values greater than .90 are usually interpreted as indicators of acceptable fit (Kline, 2011).

The tested model showed a good fit in men (RMSEA $=.117,90 \% \mathrm{Cl}$ of RMSEA $=$ $.07-.16, \mathrm{CFI}=.95, \mathrm{TLI}=.91, \mathrm{GFI}=.96) . \mathrm{No}$ improvements were indicated by the modification indices. RMSEA value was under .10, therefore this value was considered acceptable. In addition, and as suggested by Kline (2011), when models are simpler - meaning they have low degrees of freedom- as it is the case here, RMSEA values get higher. Although modification indices were again checked, no improvement was suggested. Figure 1 shows the path diagram of the model in men. Standardized loadings ranged from .62 (item 6) to .82 (item 2). Squared Multiple Correlations ranged from .35 (item 5) to .66 (item 2), with a mean SMC value of .47 indicating that, on average, $47 \%$ of the variance in the variables was accounted for by a latent factor.

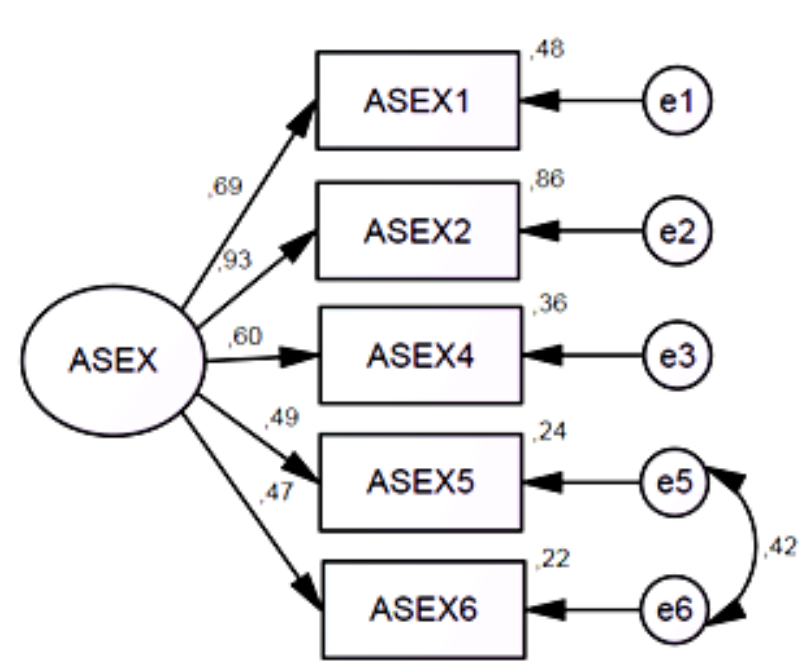

Figure 2. Factor loadings of the unidimensional structure of the ASEX in women.

In women, the unidimensional model did not reach a good fit, considering most of the indices (RMSEA $=.202,90 \% \mathrm{Cl}$ of RMSEA $=.16$ $.24, \mathrm{CFI}=.87, \mathrm{TLI}=.74, \mathrm{GFI}=.92)$. When considering the modification indices, we observed that if the analysis would be repeated treating the covariance between errors from items 5 and 6 as a free parameter, the discrepancy would fall by at least 62.46. Therefore, the errors from both items were covaried. When doing so, the model improved (RMSEA $=.09,90 \% \mathrm{Cl}$ of RMSEA $=.05-.14, \mathrm{CFI}=.97, \mathrm{TLI}=.94, \mathrm{GFI}=.98$ ) Figure 2 shows the path diagram of the model in women. Standardized loadings ranged from .47 (item 6) to .93 (item 2). Squared Multiple Correlations ranged from .28 (item 6) to .78 (item 2 ), with a mean SMC value of .44 indicating that, on average, $44 \%$ of the variance in the variables was accounted for by latent factor.

\section{- ITEM ANALYSIS AND RELIABILITY}

Table 3 presents the item analysis of the ASEX in men and women. Results showed that means were under the theoretical midpoint of the scale (i.e., 3.5). The highest mean (indicating worse sexual functioning ) was obtained, for both men and women, in item 5 (easiness to reach an orgasm); while the lowest mean was obtained in item 3 in men (easiness to get and keep erection) and in item 6 in women (satisfactory orgasms). 
Table 3

Inter-items correlations of the ASEX for men and women $(N=705)$

\begin{tabular}{|c|c|c|c|c|c|c|}
\hline & ASEX1 1 & ASEX2 & ASEX3 & ASEX4 & ASEX5 & $\begin{array}{l}\text { ASEX } \\
\text { Global }\end{array}$ \\
\hline ASEX1: Sexual interest & - & $.61^{* * *}$ & $.42^{\star * \star}$ & $.37^{* * *}$ & $.45^{\star * *}$ & $.78^{\star * \star}$ \\
\hline ASEX2: Sexual arousal & $.65^{* \star *}$ & & $.59 * * \star$ & $.47^{* \star *}$ & $.45^{\star \star *}$ & $.81^{* * *}$ \\
\hline ASEX3 & & & & & & \\
\hline Erection (men) & & & - & $.47^{* * *}$ & $.49^{* * *}$ & $.79 * * *$ \\
\hline Vaginal lubrication (women) & $.41^{* \star *}$ & $.55^{\star \star \star}$ & & & & \\
\hline ASEX4: Ability to reach orgasm & $.26^{* \star *}$ & $.47^{\star \star \star}$ & $.37 * * \star$ & - & $.42^{\star \star \star}$ & $.72^{\star \star \star}$ \\
\hline $\begin{array}{l}\text { ASEX5: Satisfaction with } \\
\text { orgasm }\end{array}$ & $.35^{\star \star \star}$ & $.42^{\star \star \star}$ & $.33^{\star * \star}$ & $.55^{\star \star \star}$ & - & $.74^{* * *}$ \\
\hline ASEX Global & $.72^{\star \star \star}$ & $.83^{\star * \star}$ & $.72^{\star \star \star}$ & $.72^{\star \star \star}$ & $.73^{\star \star \star}$ & - \\
\hline
\end{tabular}

It is noteworthy to mention that in women, while they reported to have difficulties in reaching an orgasm, also reported being satisfied with their orgasms. Standard deviations were all very close or over 1.00, with the exception of item 6 in women, which was a bit higher $(S D=1.12)$. This means that the female participants reported an average level of sexual functioning (except for satisfactory orgasms). Corrected item-total correlations ranged from .53 (item 5) to .71 (item $2)$, both in women. Finally, Cronbach's alpha was .81 for men and .79 for women. Moreover, all inter-item correlations were significant. In men, the values ranged from $r=.37, p<.001$ (item 1 and item 4) to $r=.81, p<.001$ (item 2 and global score of ASEX) and in women between $r=$ $.26, p<.001$ (item 1 and item 4) and $r=.83, p$ $<.001$ (item 2 and global score of ASEX).

\section{-EVIDENCE OF VALIDITY}

First, we performed a t-student test in order to compare mean differences in the items from the ASEX in men and women. Items 1, 2, 5 and 6 were able to be compared across genders. Significant differences were yielded for all the compared items and the global score, except for item 6. Table 4 shows that men, in comparison to women, reported better sexual functioning, stronger sexual desire, a greater ease in getting sexually aroused and reaching orgasm. However, the extent to which both men and women reported to be satisfied with their orgasms was very similar.

Secondly, we used zero-order correlations to test construct and concurrent validity. As predicted, higher scores on the ASEX items were associated in a negative and statistically significant way with the items of the MGH-SFQ. The values ranged from $r=-.35, p<.001$ (item 6 of ASEX that assesses satisfaction with orgasm and item 5 of MGH-SFQ that assesses sexual satisfaction), and $r=-.56, p<.001$ (item 3 of ASEX and item 4 of $M G H-S F Q$ referred to erection) in men. In women the values ranged from $r=-.37, p<$. 001 (item 6 ASEX and item 5 MGH-SFQ) and $r$ $=-.50, p<.001$ (item 1 of ASEX and item 1 of MGH-SFQ that evaluate the sexual interest). Also, high overall ASEX score was associated with the overall MGH-SFQ score (Table 4).

Regarding to concurrent validity, a negative correlation was shown between ASEX and attitudes towards sexuality, and propensity for sexual excitation. Higher sexual functioning was related to more positive attitudes towards sexuality and 
Table 4

Item analysis of the ASEX and mean differences between men and women in the items of the ASEX (N = 705)

\begin{tabular}{|c|c|c|c|c|c|c|c|c|c|c|}
\hline & \multicolumn{4}{|c|}{ Men $(n=297)$} & \multicolumn{6}{|c|}{ Women $(n=408)$} \\
\hline & $M$ & $S D$ & rit & $\alpha-i$ & $M$ & $S D$ & rit & $\alpha-i$ & $t$ & Cohen's d \\
\hline ASEX1 1 & 2.52 & 0.90 & .58 & .78 & 3.08 & 1.07 & .54 & .76 & $-7.39 * * *$ & -.56 \\
\hline ASEX2 & 2.33 & 0.85 & .70 & .75 & 3.03 & 0.99 & .71 & .71 & $-9.79 * * *$ & -.75 \\
\hline ASEX3 & 2.16 & 1.01 & .63 & .77 & - & - & - & - & - & - \\
\hline ASEX4 & - & - & - & - & 2.71 & 1.08 & .54 & .76 & - & - \\
\hline ASEX5 & 2.59 & 0.93 & .54 & .79 & 3.25 & 1.07 & .53 & .76 & $-8.69 * * *$ & -.65 \\
\hline ASEX6 & 2.23 & 0.89 & .58 & .78 & 2.32 & 1.12 & .54 & .76 & -1.21 & -.08 \\
\hline ASEX_global & 11.82 & 3.49 & - & .81 & 14.39 & 3.95 & - & .79 & $-9.14 * * *$ & -.68 \\
\hline
\end{tabular}

Note. Corrected Item Total-Correlation (rit), and Cronbach's Alpha if item deleted $(\alpha-i) .{ }^{* * *} p<.001$.

Table 5

Zero-order correlations between ASEX and all sexuality-related measures

\begin{tabular}{|c|c|c|c|c|c|c|}
\hline & MGHSFQ & SOS & SES & SIS1 & SIS2 & $\begin{array}{l}\text { Relationship } \\
\text { length }\end{array}$ \\
\hline ASEX men & $-.57 * * \star$ & $-.33^{* * *}$ & -.16 ** & $.51 * * *$ & $.20 * \star *$ & $.32 * \star *$ \\
\hline ASEX women & $-.51 * \star \star$ & $-.29 * \star \star$ & $-.28 * \star \star$ & $.44^{\star \star \star}$ & $.17 * \star *$ & $.34 * * *$ \\
\hline
\end{tabular}

higher tendency for sexual excitation. Additionally, positive correlations were found between ASEX and SIS1, as well as SIS2 and relationship length. Therefore, individuals who report higher sexual functioning also report a lower tendency to experience sexual inhibition. Moreover, their relationship length is higher as well (Table 5).

Finally, we examined discriminant validity. There were two groups: participants with difficulties in sexual functioning, and participants without difficulties using the ASEX total score. Participants were considered to have difficulties in sexual functioning if they scored 3 or more on any of the items of sexual functioning.
T-test comparisons can be seen in Table 6. All comparisons between individuals with problems with their sexual function to functional individuals were statistically significant. Results showed that functional participants evidenced greater scores on objective and subjective arousal, for both men and women, in comparison to individuals with problems with their sexual function.

\section{DISCUSSION}

The main goal of this study was to examine the psychometric properties of the Spanish version of the Arizona Sexual Experience Scale (McGahuey 
Table 6

T-test comparisons between sexually functional individuals and with sexual function difficulties

\begin{tabular}{|c|c|c|c|c|c|c|c|c|c|c|c|c|}
\hline & \multicolumn{6}{|c|}{ Men $(n=25)$} & \multicolumn{6}{|c|}{ Women $(n=24)$} \\
\hline & \multicolumn{2}{|c|}{ Functional } & \multicolumn{2}{|c|}{$\begin{array}{c}\text { Sexual } \\
\text { difficulties }\end{array}$} & \multirow[b]{2}{*}{$t$} & \multirow[b]{2}{*}{$\begin{array}{c}\text { Cohen's } \\
\quad d\end{array}$} & \multicolumn{2}{|c|}{ Functional } & \multicolumn{2}{|c|}{$\begin{array}{c}\text { Sexual } \\
\text { difficulties }\end{array}$} & \multirow[b]{2}{*}{$t$} & \multirow[b]{2}{*}{$\begin{array}{c}\text { Cohen's } \\
d\end{array}$} \\
\hline & $M$ & $S D$ & $M$ & $S D$ & & & $M$ & $S D$ & $M$ & $S D$ & & \\
\hline GR & .61 & .53 & -.80 & .57 & $6.32^{* * *}$ & 2.56 & .83 & .63 & .35 & .28 & $5.592^{\star \star \star}$ & .98 \\
\hline RSA & 19.27 & 5.06 & 13.40 & 7.47 & $2.35^{*}$ & .92 & 21.20 & 4.76 & 14.08 & 4.79 & $3.548^{* *}$ & 1.49 \\
\hline RSG & 3.82 & 1.12 & 2.30 & 1.25 & $3.26^{* *}$ & 1.28 & 4.33 & 1.22 & 2.71 & 1.14 & $3.233^{\star *}$ & 1.37 \\
\hline
\end{tabular}

Note. ${ }^{* * *} p<.001 ;{ }^{* *} p<.01 ;{ }^{*} p<.05 ; \mathrm{GR}=$ Genital Response; RSA = Ratings of Sexual Arousal; RSG = Ratings of Sexual Genital.

et al., 2008). The results showed adequate reliability as well as construct, convergent, and discriminant validity. Thus, the Spanish version of the ASEX can be employed by researchers and clinicians working with Spanish populations to assess sexual functioning.

The ASEX showed a unidimensional structure, which explained approximately 50\% of the variance in both sexes. Moreover, this structure was ratified through a confirmatory factor analysis. Thus, the unidimensional structure explained $47 \%$ of variance in men and $44 \%$ in women in the data from the second sample. It is noteworthy to highlight that this is the first time the factorial structure was analyzed, which supports the use of a global score as a measure for sexual functioning. Also, correlations among the items were significant but not high, suggesting that although the content is related, it is evaluating different areas of sexual response. Of a particular interest, in women, factorial structure better fitted when error from items regarding their ability to reach orgasm and their satisfaction were covaried. This provides an interesting finding, in contrast to men, which highlights some overlap between their ability and their satisfaction with orgasm, previously suggested by a review (Arcos-Romero \& Sierra, 2018), and shown when using the Female Sexual Functioning Index in Hispanic women with a correlation among both dimensions $(r=.82)$ (Moyano, Dib-Fayad, \& Vélez-Schemankewitz, $2017)$. Interestingly, as indicated by Paterson, Jim, Amsel and Bimik (2014), who analyzed gender differences in a laboratory, for men, resolution of arousal becomes quicker, and therefore their subjective sexual arousal decreases earlier, while for women this aspect maintained longer. It is likely that this after-orgasm experience play a role on women's overlap between their ability to reach orgasm and their orgasm's satisfaction.

Regarding evidence of validity, gender differences were found. The women reported lower global sexual functioning that than men, which was congruent with previous research (Palacios et al., 2009; Sierra et al., 2012). When considering the areas of sexual functioning, the findings were also similar to those already reported in previous studies, in which the women reported lower sexual desire, more difficulty in getting sexually aroused and more difficulty in reaching orgasm in comparison to men (Sánchez-Fuentes et al., 2016; Sierra et al., 2014). In spite of women's higher difficulties in reaching orgasm, both men and women reported to be satisfied with their orgasms. Previous research has evidenced that women with impairments in sexual desire, arousal, and orgasm could still report being satisfied with their sexual interactions (Sierra et al., 2014). This emphasizes that, in women, sexual satisfaction is not only related with their physical sexual response, but with other factors that may have more to do with intimacy or affection (Calvillo, SánchezFuentes, \& Sierra, 2018; Sánchez-Fuentes et al., 2016).

Secondly, and in agreement with the second hypothesis, better sexual functioning derived from the ASEX is also related with better sexual functioning measured by the MGH-SFQ. This 
supports convergent validity. Thirdly, better sexual functioning is associated with more positive sexual attitudes, as previously shown (Sánchez-Fuentes et al., 2016). Further, there is a relationship, although weak, between better sexual functioning and higher propensity for sexual excitation (Bancroft et al., 2009; Moyano \& Sierra, 2014). Consistent with our hypothesis, lower sexual functioning is associated with greater sexual inhibition due to fear of sexual performance failures (SIS1). It is well-known that men and women who have difficulties with their sexual functioning also report more worries regarding their performance (Bancroft \& Janssen, 2000; Moyano \& Sierra, 2014); and, also, focusing in sexual performance is associated with performance anxiety, which leads to more sexual dysfunctions (Wiederman, 2001). Fourthly, lower sexual functioning was related with more sexual inhibition due to the risk of being caught/getting an STI during sex (SIS2). In previous research, Moyano and Sierra (2014) found that sexual functioning was more strongly related with SIS1 than with SIS2, as SIS 1 acts as a trait, while SIS2 has more to do with external threats (Bancroft et al., 2009). Finally, individuals who were in a longer relationships reported more impairment with their sexual functioning, which is consistent with previous findings in which lower satisfaction is linked to worse sexual functioning (Sánchez-Fuentes \& Sierra, 2015).

McGahuey et al. (2000) proposed that scores of 19 or more, and/or scores or five or more in one or more items, and scores of four or more in three or more items are indicators of sexual dysfunction. In the present study, we analyzed the discriminant validity by comparing participants with low scores to those with high scores in the ASEX, however we could not consider the latter group as dysfunctional. The mean global score from the ASEX in men was 14.40 $(S D=1.78)$ and in women equal to 14.71 (SD $=1.64)$. Our findings showed that participants with lower sexual functioning reported lower subjective sexual arousal with visual sexual stimuli. That is, they reported lower sexual arousal and genital sensations (Laan et al., 2008). Moreover, participants with worse sexual function also showed lower levels of objective sexual arousal (Sarin et al., 2014). This finding is of special relevance, as it shows that the ASEX has adequate discriminant validity, even for distinguishing differences between individuals with low and high scores -although non-dysfunctional scores are found, which supports its use in both clinical and research contexts.

In spite of the adequate psychometric properties of the ASEX, it is required to mention the limitations from this study. The main limitation is that findings cannot be generalized to the general Spanish population, as participants were recruited through incidental sampling and only data from heterosexual individuals was considered. Also, most of the sample reported optimum sexual functioning. Future research should examine the psychometric properties of the Spanish version of the ASEX in more representative samples, as well as in other minority samples (LGBTI) and clinical samples. Likewise, it will be interesting to adapt the ASEX in Spanish-speaking sample in order to expand its use, since it is known that the functioning of the items may vary depending on the country (Benítez-Borrego, Mancho-Fora, Farràs-Permanyer, Urzúa-Morales, \& GuàrdiaOlmos, 2016; Bringas-Molleda et al., 2017).

It is noteworthy to remark that most of the sexual self-reported measures are commonly validated assuming that sexual experiences that participants refer to, often occur in a consensual context. However, this aspect, often neglected in research, should be taken into account, as, unfortunately, some sexual experiences are not consensual or forced, and both sexual experiences are not the same (De Zutter, Horselenberg, \& van Koppen, 2017). More evidences of validity, exploring sexual functioning in both victims of sexual harassment and sexual offenders or aggressors would provide a multicontext measure, by also considering the impact of perceptions and ideology, which have several implications on sexual experiences of harassment (Herrera, Herrera, \& Expósito, 2018), as well as attitudes and types of aggression have on sexual aggression (Moyano, Monge, \& Sierra, 2017). Align with this, some recent studies are aimed to develop scales that are able to capture the therapeutic effectiveness of treatment of sexual aggressors (see Martínez-Catena \& Redondo, 2017). In this sense, a longitudinal study should provide validity for the ASEX as a follow up measure.

Nonetheless, the ASEX is a self-reported measure with adequate psychometric properties, reliability and validity to assess sexual functioning, which provides a global score and also information 
from specific areas of sexual response in Spanish men and women. For this reason, the ASEX can be useful for both clinical and research contexts, such as primary assistance, in which sexual functioning is still a frequently neglected issue.

\section{- Funding}

This research has been funded through the Research Projects PSI2010-15719 (Ministry of Science and Innovation) and PSI2014-25035-R (Ministry of Economy and Competitiveness).

\section{- Conflict of interest}

The authors declare no conflict of interest.

\section{REFERENCES}

American Psychiatric Association. (2013). Diagnostic and statistical manual of mental disorders $\left(5^{\text {th }}\right.$ ed.). Washington, DC: American Psychiatric Association.

Arcos-Romero, A. I., \& Sierra, J. C. (2018). Revisión sistemática sobre la experiencia subjetiva del orgasmo. Revista Internacional de Andrología, 16(2), 75-81. https://doi.org/10.1016/i. androl.2017.09.003

Bancroft, J., Graham, C. A., Janssen, E., \& Sanders, S. A. (2009). The Dual Control Model: Current status and future directions. Journal of Sex Research, 46, 121-142. doi: http://dx.doi. org/10.1080/00224490902747222

Bancroft, J., \& Janssen, E. (2000). The dual control model of male sexual response: A theoretical approach to centrally mediated erectile dysfunction. Neuroscience and Biobehavioral Reviews, 24, 571-579. doi: http://dx.doi. org/10.1016/S0149-7634(00)00024-5

Benítez-Borrego, S., Mancho-Fora, N., FarràsPermanyer, L., Urzúa-Morales, A., \& GuàrdiaOlmos, J. (2016). Differential item functioning of WHOQOL-BREF in nine lberoamerican countries. Revista Iberoamericana de Psicología y Salud, 7, 51-59. doi: http://dx.doi.org/10.1016/i. rips.2016.04.001

Briki, M., Haffen, E., Monnin, J., Tio, G., Nicolier, M., Sechter, D., ...Vandel, P. (2014). Sexual dysfunction and depression: Validity of a French version of the ASEX scale. Encephale, 40, 114-122. doi: http://dx.doi.org/10.1016/i. encep.2012.10.008
Bringas-Molleda, C., Estrada-Pineda, C., SuárezÁlvarez, J., Torres, A., Rodríguez-Díaz, F. J., ...Rodríguez-Franco, L. (2017). Sexist and transcendent attitude during courtship between Latin American university students. Revista Iberoamericana de Psicología y Salud, 8, 44-55. doi: http://dx.doi.org/10.23923/i. rips.2017.08.005

Browne, M. W., \& Cudeck, R. (1993). Alternative ways of assessing model fit. In K. A. Bollen, \& J. S. Long (Eds.), Testing structural equation models (pp. 136-162). Bervely Hills, CA: Sage.

Calvillo, C., Sánchez-Fuentes, M. M., \& Sierra, J. C. (2018). Revisión sistemática sobre la satisfacción sexual en parejas del mismo sexo. Revista Iberoamericana de Psicología y Salud, 9, 115-136. doi: https://doi.org/10.23923/i. rips.2018.02.018

De Zutter, A. W., Horselenberg, R., \& Van Koppen, P. J. (2017). Filing false vice reports: Distinguishing true from false allegations of rape. European Journal of Psychology Applied to Legal Context, 9, 1-14. https://doi.org/10.1016/i. eipal.2016.02.002

Granados, M. R., Salinas, J. M., \& Sierra, J. C. (2017). Spanish version of the Sexual Excitation/ Sexual Inhibition Inventory for Women: Factorial structure, reliability and validity evidences. International Journal of Clinical and Health Psychology, 17, 46-55. doi: http://dx.doi. org/10.1016/i.ijchp.2016.09.003

Janssen, E., Vissenberg, M., Visser, S., \& Everaerd, W. (1997). An in vivo comparison of two circumferential penile strain gauges: Introducing a new calibration method. Psychophysiology, 34, 717-720. doi: http://dx.doi. org/10.1111/i.1469-8986.1997.tb02147.x

Herrera, M. C., Herrera, A., \& Expósito, F. (2018). To confront versus not to confront: Women's perception of sexual harassment. European Journal of Psychology Applied to Legal Context, 10, 1-7. doi: https://doi.org/10.1016/i. eipal.2017.04.002

Jitkritsadakul, O., Jagota, P., \& Bhidayasiri, R. (2014). The Arizona Sexual Experiences Scale: A Validity and Reliability Assessment of the Thai Translation (ASEX-Thai) in Parkinson's Disease. Journal of Parkinson's Disease, 4, 205-210. doi: 
http://dx.doi.org/10.3233/JPD-130271

Kline, R. B. (2011). Principles and practice of structural equation modelling. New York, NY: Guilford Press.

Laan, E., Everaerd, W., \& Evers, A. (1995). Assessment of female sexual arousal: Response specificity and construct validity. Psychophysiology, 32, 476-485. doi: http:// dx.doi.org/10.1111/i.1469-8986.1995. tb02099.x

Laan, E., van Driel, E. M., \& van Lunsen, R. H. W. (2008). Genital responsiveness in healthy women with and without sexual arousal disorder. Journal of Sexual Medicine, 5, 1424-1435. doi: $\quad$ htp://dx.doi.org/10.1111/i.17436109.2008.00827.x

Laumann, E. O., Paik, A., \& Rosen, R. C. (1999). Sexual dysfunction in the United States: Prevalence and predictors. Jama, 281, 537-544. doi: http://dx.doi.org/10.1001/ jama.281.6.537

Martínez-Catena, A., \& Redondo, S. (2017). Psychological treatment and therapeutic change in incarcerated rapists. European Journal of Psychology Applied to Legal Context, 9, 41-49. doi: http://dx.doi.org/10.1016/i. ejpal.2016.11.001

McGahuey, C. A., Gelenberg, A. J., Laukes, C. A., Moreno, F. A., Delgado, P. L., McKnight, K. M., ...Manber, R. (2000). The Arizona Sexual Experience Scale (ASEX): Reliability and Validity. Journal of Sex \& Marital Therapy, 26, 25-40. doi: http://dx.doi.org/10.1080/009262300278623

McGahuey, C. A., Gelenberg, A. J., Laukes, C. A., Moreno, F. A., Delgado, P. L., McKnight, K. M., ...Manber, R. (2008). ASEX-Spain/SpanishVersion of 01 Jul 08. Unpublished manuscript, Department of Psychiatry, University of Arizona, Tucson, USA.

Moyano, N., Dib-Fayad, N., \& Vélez-Schemankewitz, M. (2017). Adaptation and validation of the sexual self-consciousness scale in Ecuadorian women. Sexual and Relationship Therapy, 32, 155-172. https://doi.org/10.1080/14681994. 2017.1295137

Moyano, N., Monge, F. S., \& Sierra, J. C. (2017). Predictors of sexual aggression in adolescents: Gender dominance vs. rape supportive attitudes.
European Journal of Psychology Applied to Legal Context, 9, 25-31. https://doi.org/10.1016/i. eipal.2016.06.001

Moyano, N., \& Sierra, J. C. (2014). Validación de las Escalas de Inhibición Sexual/Excitación SexualForma Breve (SIS/SES-SF). Terapia Psicológica, 32, 87-100. doi: http://dx.doi.org/10.4067/ S0718-48082014000200002

Nakhli, J., El Kissi, Y., Bouhlel, S., Amamou, B., Nabli, T. A., Nasr, S. B., ...Ali, B. B. (2014). Reliability and validity of the Arizona Sexual Experiences Scale-Arabic version in Tunisian patients with schizophrenia. Comprehensive Psychiatry, 55, 1473-1477. doi: http://dx.doi.org/10.1016/i. comppsych.2014.04.006

Palacios, S., Castaño, R., \& Grazziotin, A. (2009). Epidemiology of female sexual dysfunction. Maturitas, 63, 119-123. doi: https://doi. org/10.1016/i.maturitas.2009.04.002

Paterson, L. Q. P., Jin, E. S., Amsel, R., \& Binik, Y. M. (2014). Gender similarities and differences in sexual arousal, desire and orgasmic pleasure in the laboratory. Journal of Sex Research, 51 (7), 801 813. doi: $10.1080 / 00224499.2013 .867922$

Sánchez-Fuentes, M. M., Salinas, J. M., \& Sierra, J. C. (2016). Use of an ecological model to study sexual satisfaction in a heterosexual Spanish sample. Archives of Sexual Behavior, 45, 19731988. doi: http://dx.doi.org/10.1007/s10508016-0703-9

Sánchez-Fuentes, M. M., \& Sierra, J. C. (2015). Sexual satisfaction in a heterosexual and homosexual Spanish sample: The role of sociodemographic characteristics, health indicators, and relational factors. Sexual and Relationship Therapy, 30, 226-242. doi: http://dx.doi.org/1 0.1080/14681994.2014.978275

Sarin, S., Amsel, R., \& Binik, Y. M. (2014). How hot is he? A physiological and psychosocial examination of the arousal patterns of sexually functional and dysfunctional men. The Journal of Sexual Medicine, 11, 1725-1740. doi: http:// dx.doi.org/10.1111//sm.12562

Sierra, J. C., Arcos-Romero, A. I., Granados, M. R., Sánchez-Fuentes, M. M., Calvillo, C., \& Moyano, N. (2017). Escalas de Valoración de Excitación Sexual y Valoración de Sensaciones Genitales: propiedades psicométricas en muestras 
españolas. Revista Internacional de Andrología, 15, 99-107. doi: http://dx.doi.org/10.1016/i. androl.2016.10.008

Sierra, J. C., Granados, R., Sánchez-Fuentes, M. M., Moyano, N., \& López, C. (2015, July). Activación sexual ante estímulos sexuales visuales: Comparación entre hombres y mujeres. Poster presented at the XXXV Congreso Interamericano de Psicología, Lima (Perú).

Sierra, J. C., Moyano, N., Vallejo-Medina, P., \& Gómez-Berrocal, C. (2018). An abridged Spanish version of Sexual Double Standard Scale: Factorial structure, reliability and validity evidence. International Journal of Clinical and Health Psychology, 18, 69-80. doi: http://dx.doi. org/10.1016/i.ijchp.2017.05.003

Sierra, J. C., Vallejo-Medina, P., Santos-Iglesias, P., \& Lameiras-Fernández, M. (2012). Validación del Massachusetts General Hospital-Sexual Functioning Questionnaire (MGH-SFQ) en población española. Atención Primaria, 44, 516-526. doi: http://dx.doi.org/10.1016/i. aprim.2012.02.004

Sierra, J. C., Vallejo-Medina, P., Santos-Iglesias, P., Moyano, N., Granados, M. R., \& Sánchez-
Fuentes, M. M. (2014). Funcionamiento sexual en personas mayores: influencia de la edad y de factores psicosexuales. Revista Internacional de Andrología, 12, 64-70. doi: http://dx.doi. org/10.1016/i.androl.2013.10.002

Soykan, A. (2004). The reliability and validity of Arizona Sexual Experiences Scale in Turkish ESRD patients undergoing hemodialysis. International Journal of Impotence Research, 16, 531-534. doi: htp://dx.doi.org/10.1038/si.iiir.3901249

Vallejo-Medina, P., Granados, M. R., \& Sierra, J. C. (2014). Propuesta y validación de una versión breve del Sexual Opinion Survey en población española. Revista Internacional de Andrología, 12, 47-54. doi: http://dx.doi.org/10.1016/i. androl.2013.04.004

Wiederman, M. W. (2001). Gender differences in sexuality: Perceptions, myths, and realities. The Family Journal, 9, 468-471. doi: http://dx.doi. org/10.1177/1066480701094019

World Health Organization. (2015). Sexual health, human rights and the law. Retrieved from: $\quad$ http://apps.who.int/iris/bitstream/ 10665/175556/1/9789241564984 eng.pdf? ua $=1$ 